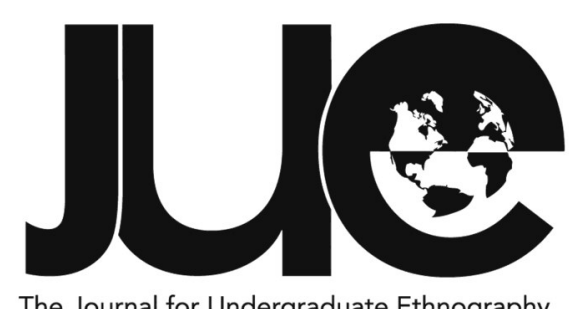

The Journal for Undergraduate Ethnography

\title{
Editor's Welcome
}

\section{Martha Radice, Editor-in-Chief}

\section{Dalhousie University, radice@undergraduateethnography.org}

Welcome to another issue of The Journal for Undergraduate Ethnography, which wraps up our tenth volume. This issue opens with two articles examining dimensions of identity in the USA: Samantha Pentecost explores expressions of hegemonic masculinity at a co-ed scout camp, and Mary Heinz looks at the formation of furry LGBT+ identity and community online. Lorena Reinert then takes us to Asháninka territory in the Peruvian Amazon to show how Asháninka epistemologies sustain resistance to colonial oppression. The next two articles focus on France. Mariel Tabachnick investigates French college students' views on how Muslims fit into France's assertively secular society. Anqi Chen and Yongxin Lu analyze patterns of integration among Chinese immigrants in the Triangle de Choisy, the best-known quartier chinois of Paris. (Our cover photo, a creative commons image by Myrabella, depicts Chinese New Year 2015 in that neighbourhood.) Finally, continuing the migration theme, Yuxian Seow lyrically explores everyday transnationalism through the mutual care and loving communication she sustains with her grandmother. 
W ith this issue, we welcome Karen McGarry, who joins the JUE team in the role of Co-Editor. Dr McGarry is an associate professor in the Department of Anthropology at McMaster University (Hamilton, Ontario, Canada). Her earlier research examined how Canadian nationalism was performed along with more particular identities of race, class, gender, and sexuality in the arena of Olympic-level figure skating. Her recent research focuses on currents of masculinity in high-performance swimming and scuba-diving tourism in the Virgin Islands. She is also coauthor of Practicing Ethnography: $A$ Student Guide to Method and Methodology (written with Lynda Mannik, published by University of Toronto Press, 2017), an engaging and practical textbook that brings doing ethnography in contemporary North American cultures to life. I'm delighted to be sharing the editorial work with such an expert colleague.

It goes without saying that the months since the publication of vol. 10 no. 1 in February 2020 have been challenging. I want to express particular thanks to all the members of our Senior Editorial Board, named on the inside front cover. They have upheld their commitment to reviewing and rereviewing article submissions even as they shoulder the extra burdens placed on professors and researchers during the pandemic. I would also like to recognize the indispensable assistance of Briana Kelly and the support of Dalhousie University Libraries, whose infrastructure hosts this journal in Mi'kma'ki, the ancestral and unceded territory of the Mi'kmaq People.
Ten years is already an impressive lifespan for an undergraduate journal, and thanks to the continued commitment of everyone on the team of The Journal for Undergraduate Ethnography, we are well set for at least ten more. 